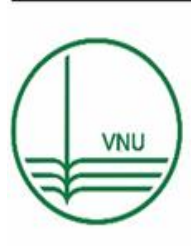

VNU Journal of Science: Legal Studies

Journal homepage: https://js.vnu.edu.vn/LS

\title{
Original Article \\ Applying Human Right - Based Approach in Constitutional Rights Guarantee in Vietnam
}

\author{
Nguyen Thuy Duong* \\ VNU School of Law, Vietnam National University, Hanoi, \\ 144 Xuan Thuy, Cau Giay, Hanoi, Vietnam
}

Received 17 April 2020

Revised 25 May 2020; Accepted 23 June 2020

\begin{abstract}
The provisions on human rights and civil rights in the 2013 Constitution have marked a progress in constitutional reform. However, the implementation of constitutional rights have still faced many challenges in practice. One of these challenges is inappropriate awareness on human rights of public actors as well as the people. A rights-based approach, an approach that pays equal attention to what should be done and to how it should be done, will contribute to better constitutional rights realization by raising both awareness of right-holders and the sense of responsibility of dutybearers.
\end{abstract}

Keywords: human right-based approach, human rights, constitutional rights implementation.

\footnotetext{
* Corresponding author.

Email address: tduong_nguyen@ymail.com

https://doi.org/10.25073/2588-1167/vnuls.4265
} 


\title{
Áp dụng phương pháp tiếp cận dựa trên quyền trong việc bảo đảm thực thi các quyền hiến định ở Việt Nam
}

\author{
Nguyễn Thùy Dương* \\ Khoa Luật, Đại học Quốc gia Hà Nội, 144 Xuân Thủy, Cầu Giấy, Hà Nội \\ Nhận ngày 17 tháng 4 năm 2020 \\ Chỉnh sửa ngày 25 tháng 5 năm 2020; Chấp nhận đăng ngày 23 tháng 6 năm 2020
}

\begin{abstract}
Tóm tắt: Các quy định về quyền con người, quyền công dân trong Hiến pháp 2013 đã đánh dấu một bước tiến lớn trong sự phát triển của chế định này tại nước ta. Tuy nhiên việc thực thi các quyền hiến định vẫn còn nhiều trở ngại trên thực tế. Một trong số đó là nhận thức, ý thức về quyền con người của các chủ thể công quyền cũng như người dân. Tiếp cận dựa trên quyền, phương pháp tiếp cận quyền dành sự chú trọng như nhau đối với cả nội hàm quyền và cách thức thực thi quyền, sẽ đem lại những chuyển biến tích cực cho việc thực thi các quyền hiến định trên thực tế thông qua việc nâng cao nhận thức của chủ thể thụ hưởng quyền cũng như tinh thần trách nhiệm của chủ thể có nghĩa vụ.
\end{abstract}

Tư khóa: tiếp cận dựa trên quyền; quyền con người, thực thi quyền hiến định.

\section{Quyền con người và tiếp cận dựa trên quyền}

Ngày này, quyền con người được coi là giá trị chung của toàn nhân loại, thuộc về mọi cá nhân mà không có bất cứ sự phân biệt đối xử nào dựa trên các cơ sở về chủng tộc, quốc tịch, nơi cư trú, giới tính, nguồn gốc dân tộc, màu da, tôn giáo, ngôn ngữ hoặc bất kỳ cơ sở nào khác. ${ }^{1}$ Quyền con người là những bảo đảm pháp lý toàn cầu trên các lĩnh vực dân sự, chính trị, kinh tế, xã hội và văn hóa, bảo vệ các cá nhân/nhóm chống lại các hành động hoặc sự bỏ mặc làm tổn hại đến các quyền, tự do cơ bản, nhân phẩm [1]. Ngoài nguyên tắc về tính phổ quát, các nguyên tắc khác như tính không thể tước bỏ, không thể phân chia, tính liên hệ và phụ thuộc lẫn nhau cũng được phản ánh thông qua các quy định về quyền con người trong các điều ước quốc tế, các văn kiện của khu vực và pháp luật các nước, trong đó có Hiến pháp, đạo luật có giá trị pháp lý tối cao trong hệ thống pháp luật quốc gia.

Tiếp cận dựa trên quyền là phương pháp tiếp cận chú trọng cả các nguyên tắc và các tiêu chuẩn về nhân quyền, trong đó các nguyên tắc nêu trên được coi là điều kiện của quá trình đảm bảo quyền và các tiêu chuẩn về nhân quyền ${ }^{2}$ được coi là kết quả của quá trình đó. Cụ thê, phương pháp tiếp cận dựa trên quyền (Human Rights Based Approach - HBRA) là phương pháp tiếp cận dựa trên sự cân bằng giữa hai yếu tố: nội dung quyền và cách thức thực thi quyền. Nói cách khác, phương pháp tiếp cận dựa trên quyền là phương pháp tiếp cận quyền dành sự quan tâm như nhau đối với nội hàm của quyền và việc quyền đó

\footnotetext{
* Tác giả liên hệ.

Địa chỉ email: tduong_nguyen@ymail.com

https://doi.org/10.25073/2588-1167/vnuls.4265

${ }^{1}$ Điều 2, Tuyên ngôn nhân quyền 1948 ghi nhận nguyên tắc không phân biệt đối xử đối với việc thụ hưởng các quyền và tự do cơ bản trên mọi lĩnh vực chính trị, dân sự, kinh tế, văn hóa, xã hội.

2 Tiêu chuẩn về quyền con người thể hiện mức độ tối thiểu chấp nhận được của việc thụ hưởng quyền, ví dụ như phổ cập giáo dục tiểu học phổ cập, tiếp cận phổ cập các dịch vụ y tế, an sinh xã hội cơ bản.
} 
được thực thi như thế nào trên thực tế [2]. Theo phương pháp này, quyền con người được đảm bảo cả trên những quy định về mặt pháp lý và cả ở quy trình xác lập, ban hành và thực hiện các quy định đó. Như vậy, quá trình thực thi quyền sẽ phải dựa trên cơ sở, điều kiện là các tiêu chuẩn/nguyên tắc về quyền con người. Áp dụng phương pháp này góp phần tạo cơ hội nhiều hơn cho cá nhân thụ hưởng các quyền con người trên thực tế đặc biệt là những nhóm yếu thế trong xã hội bởi vì nó vừa có thể nâng cao nhận thức của các cá nhân về quyền lợi của mình, vừa có thể tăng khả năng chịu trách nhiệm của chủ thể có trách nhiệm thực thi quyền.

\section{2. Áp dụng tiếp cận dựa trên quyền trong việc đảm bảo thực thi các quyền hiến định}

Tình huống nhân quyền bao quát ở một quốc gia thường được đánh giá trước hết ở các quy định bảo đảm quyền con người, quyền công dân trong hiến pháp và mức độ tuân thủ hiến pháp của các chủ thể công quyền. Đây cũng là hai khía cạnh phản ánh vị trí trung tâm của hiến pháp đời sống người dân các quốc gia trên thế giới. Hiến pháp với tư cách là văn bản có hiệu lực pháp lý cao nhất trong hệ thống pháp luật quốc gia, không có bất cứ đạo luật biện pháp pháp lý nào có thể trái với hiến pháp. Hay nói một cách khác, nếu một đạo luật hoặc biện pháp pháp lý được cơ quan lập pháp thông qua mà không phù hợp với hiến pháp, thì sẽ bị tuyên bố vô hiệu bởi chủ thể có thẩm quyền. Quyền con người được coi như là trung tâm trong trật tự hiến định của nhà nước hiện đại, không chỉ xác lập mối quan hệ giữa cá nhân, nhóm và Nhà nước, mà còn thiết lập cấu trúc nhà nước, các quy trình ra quyết định và giám sát. Do đó, các quy định về quyền con người, quyền công dân là một phần không thể thiếu trong hiến pháp hiện đại. Đồng thời, những hạn chế trong việc thực thi quyền con người, dù là quyền cá nhân hay quyền tập thể, ở cấp độ quốc gia thường bắt nguồn từ những thiếu sót trong hiến pháp. Áp dụng tiếp cận dựa trên quyền đối với việc thực các quyền hiến định không những cho phép các chủ thể thụ hưởng quyền cũng như các chủ thể có nghĩa vụ phát hiện ra những thiếu sót trong Hiến pháp mà còn góp phần củng cố cơ chế hiến định về quyền con người cả về mặt thể chế và thiết chế. Bên cạnh đó, các nguyên tắc áp dụng phương pháp tiếp cận dựa trên quyền về cơ bản cũng phù hợp với các nguyên tắc hiến định về quyền con người, đó là: tham gia; trách nhiệm; bình đẳng và không phân biệt đối xử; trao quyền và tính hợp pháp.

Về mặt thể chế, tiếp cận dựa trên quyền đảm bảo sự tham gia người dân vào việc xây dựng các quy định về quyền con người trong hiến pháp. Mối liên hệ giữa quyền con người và hiến pháp thường bắt đầu bằng quá trình thông qua hiến pháp hoặc cải cách hiến pháp vì quá trình này thể hiện sự tham gia của các thành phần trong xã hội. Càng có sự tham gia rộng rãi của tất cả mọi thành phần trong xã hội thì những quá trình này càng được đánh giá là thành công, thể hiện thông qua việc người dân có thể nêu quan điểm của mình và thảo luận một cách tự do mà không gặp trở ngại nào từ phía nhà cầm quyền. Cần lưu ý rằng những ý kiến và quan điểm này phải được xem xét trong khuôn khổ các thủ tục rõ ràng, và những người chịu trách nhiệm giám sát quá trình này là công bằng và vô tư [3]. Những điều kiện như vậy chỉ có thể đạt được trên thực tế khi đầy đủ các khía cạnh của tự do ngôn luận, bao gồm quyền truyền đạt ý kiến của một người khác, quyền tự do truyền thông, tự do lập hội và hội họp [4], được bảo đảm.

Tiếp cận dựa trên các quyền hiến định còn nhấn mạnh trách nhiệm tuân thủ hiến pháp của các chủ thể có nghĩa vụ. Tuân thủ hiến pháp đồng nghĩa với việc tuân thủ các quy định về quyền, tự do cơ bản của con người. Các chủ thể công quyền phải chịu trách nhiệm cho hành vi không phù hợp với hiến pháp do mình thực hiện. Hiến pháp được coi là bảo đảm pháp lý cao nhất cho cuộc sống và phúc lợi cho người dân, cũng như công cụ cơ bản để định hướng trật tự xã hội và tổ chức Nhà nước. Hiến pháp với tư cách là đạo luật tối cao, được coi là trung tâm của đời sống chính trị - xã hội của quốc gia, xác định mối quan hệ giữa Nhà nước và người dân, giữa các cơ quan thực hiện các chức năng khác nhau của Nhà nước. Hiến pháp đảm bảo sự ổn định về chính trị và xã hội, đặc biệt trong các tình huống hậu xung 
đột, hiến pháp thường đóng vai trò thúc đẩy và bảo vệ hòa bình, ngăn chặn căng thẳng và xung đột tái diễn thông qua các thể chế dân chủ và bảo vệ các quyền. Trong thời kỳ quá độ, hiến pháp còn có thể trở thành một công cụ những định hướng cho những thay đổi trong đời sống chính trị và xã hội, duy trì nền hòa bình và ổn định một cách lâu dài [5].

Về mặt thiết chế, việc áp dụng phương pháp tiếp cận dựa trên quyền góp phần hiện thực hóa mục đích của hiến pháp, đó là xây dựng một nền quản trị tốt vì quyền con người. Khái niệm quản trị tốt ở đây cần phải được hiểu dựa trên các nguyên tắc thiết yếu của chủ nghĩa hiến pháp hiện đại. Theo đó, các thành tố của quản trị tốt là các quy trình hoạch định chính sách có thể dự đoán, công khai và minh bạch; đội ngũ công chức thấm nhuần đạo đức nghề nghiệp; cơ quan hành pháp/chính phủ chịu trách nhiệm cho hành động của mình; một xã hội dân sự mạnh mẽ có khả năng tham gia vào các vấn đề công cộng; và tất cả mọi hành vi đều được đặt dưới sự điều chỉnh của pháp luật [6]. Các nguyên tắc áp dụng tiếp cận dựa trên quyền cũng chính là những nguyên tắc chung của chủ nghĩa hiến pháp và nền dân chủ hiện đại bao gồm [7 - 9]: sự tham gia; phân chia quyền lực; pháp quyền; công khai, minh bạch; trách nhiệm.

Mặt khác, các ghi nhận trong hiến pháp tạo cơ sở pháp lý vững chắc cho việc áp dụng phương pháp tiếp cận dựa trên quyền. Hiến pháp là một trong những nhân tố quan trọng đảm bảo sự ổn định về chính trị và xã hội của một quốc gia, có thể được xem xét từ nhiều góc độ khác nhau. Từ góc độ thể chế, một hiến pháp xác lập những nguyên tắc quản trị công. Từ góc độ dân chủ, hiến pháp bảo đảm quyền lợi của người dân và chống lại những sự cai trị độc đoán. Từ góc độ chính trị, một hiến pháp xác định tính chính danh của chủ thể nắm quyền lực và các thể chế và thủ tục mà thông qua đó quyền lực tối cao được thực thi. Từ góc độ đạo đức, một hiến pháp thể hiện các giá trị cơ bản làm cơ sở cho Nhà nước và xã hội. Cuối cùng, từ góc độ pháp lý, hiến pháp là luật cơ bản của một quốc gia và là nền tảng cho toàn bộ hệ thống pháp luật. Hiến pháp có giá trị pháp lý tối cao, các đạo luật khác không được trái với hiến pháp. Hiến pháp thiết lập các cơ chế thực thi và giải thích pháp luật trong các trường hợp vi phạm hoặc tranh chấp. Các bản hiến pháp hiện đại được coi là "khế ước xã hội, có khả năng chi phối đời sống của cả cộng đồng. Về mặt lý thuyết, bản khế ước đó không được coi là giữa nhà nước nước với người dân mà là giữa những người dân, trong đó, nhân dân tự tổ chức và định hình nên nhà nước của mình trên cơ sở dung hòa các lợi ích khác nhau. Một bản hiến pháp dựa trên các quyền và tự do cơ bản của con người chính là cơ sở để đảm bảo lợi ích chung của cả cộng đồng cũng như từng cá nhân trong cộng đồng.

Các hiến pháp hiện hành đều xác định một tập hợp các quyền hợp pháp của cá nhân trong mối quan hệ với Nhà nước và trong xã hội. Tập hợp các quyền này không đơn thuần chỉ là những quy định trong hiến pháp mà còn đóng vai trò là bản tuyên bố các giá trị cơ bản của xã hội, như nhân phẩm, tự do, bình đẳng, công bằng và công lý. Để làm hài hòa với các giá trị này, các quyền hiến định bảo vệ lợi ích thiết yếu của các cá nhân, như quyền đối với sức khỏe, nhà ở, an ninh cá nhân và quyền tham gia vào các hoạt động công. Thêm vào đó, mô hình hiến pháp đậm chất nhân văn cũng được coi là phát triển mới của chủ nghĩa hợp hiến. Có thể nói rằng, hiến pháp thuở mới ra đời có xu hướng tập trung vào các khía cạnh thể chế, đặc biệt là tổ chức nhà nước và các bộ phận cấu thành của nó, tuy nhiên ngày nay, cùng với nhận thức về địa vị của các cá nhân và các nhóm, cũng như hạnh phúc của người dân với tư cách là khía cạnh chủ chốt của đời sống cộng đồng, bảo đảm quyền con người đã được coi là yếu tố trung tâm của hiến pháp. Hầu hết mọi cải cách Nhà nước do nhà nước tiến hành, dù là trong lĩnh vực kinh tế, an ninh hay chính trị, đều cần có sự cân nhắc liên quan đến các quyền con người, đây được coi là một trong số các nghĩa vụ của nhà nước. Khi tiến hành sửa đổi hoặc thông qua hiến pháp mới, quyền con người cũng như các biện pháp đảm bảo các quyền này là những yếu tố đầu tiên được quan tâm. Chế định quyền con người, quyền công dân và các cơ chế, thủ tục có liên quan đóng một vai trò đặc biệt trong các xã hội tồn tại nhiều mâu thuẫn, 
cũng như trong việc đối mặt với những thách thức trong sự phát triển của các xã hội này. Việc xây dựng các chế định này cần phải tính đến những giá trị sẽ được bảo vệ trong trường hợp xung đột lợi ích, làm thế nào để đạt được sự cân bằng giữa các giá trị và lợi ích khác nhau, giữa ý chí của đa số và quyền của thiểu số. Chế định quyền con người, quyền công dân với tư cách là một chế định của hiến pháp, không được soạn thảo chỉ để sử dụng trong một thời gian ngắn, mà phải được tôn trọng và thực thi một cách lâu dài, nó không chỉ có tác dụng bảo vệ các cá nhân mà còn đóng vai trò trụ cột của một xã hội dân chủ và hài hòa. Việc áp dụng phương pháp tiếp cận dựa trên quyền sẽ đem đến một kêt quả tốt và bền vững hơn bằng cách phân tích và giải quyết sự bất bình đẳng, phân biệt đối xử và bất công chính thử thách chủ yếu trong sự phát triển của một xã hội. Tiếp cận dựa trên quyền đặt các tiêu chuẩn nhân quyền quốc tế và nghĩa vụ tương ứng của Nhà nước vào vị trí trung tâm của sự phát triển của mỗi quốc gia, đồng thời làm rõ mục đích của việc phát triển năng lực của các chủ thể, cả chủ thể có quyền (người dân) và chủ thể có nghĩa vụ (nhà nước). Cụ thể là năng lực thụ hưởng quyền của người dân và năng lực thực thi trách nhiệm của các công chức, cơ quan công quyền [10].

Trong tình huống xảy ra vi phạm nhân quyền quy mô lớn, cơ chế bảo vệ quyền con người theo hiến pháp sẽ là một trong những công cụ hiệu quả nhất để khôi phục hòa bình hoặc ngăn chặn xung đột tái diễn vì cơ chế này thể hiện lợi ích, nguyện vọng chung của cộng đồng. Mặc dù việc ghi nhận các quyền con người trong hiến pháp nghiễm nhiên tạo ra các nghĩa vụ cho nhà nước, các nghĩa vụ này vẫn cần được quy định một cách rõ ràng trong hiến pháp. Hay nói một cách khác, việc thực thi các quyền hiến định phải dựa trên cơ sở các quy định về quyền của người dân và nghĩa vụ của nhà nước. Do vậy, các quyền hiến định chỉ có thể được bảo đảm trên thực tế khi cả chủ thể thụ hưởng quyền và chủ thể có nghĩa vụ đều nhận thức được về quyền và nghĩa vụ của mình. Thêm vào đó, sự trao quyền và bảo vệ đối với người dân cần phải dựa trên sự thừa nhận rằng con người/công dân là chủ thề quyền chứ không chỉ là những cá thể nhận dịch vụ do Nhà nước cung cấp. Như vậy, tiếp cận dựa trên quyền trong hiến pháp có nghĩa các tiêu chuẩn, nguyên tắc, bảo đảm quyền con người phải coi như vấn đề cốt lõi của hiến pháp [11].

\section{Một số giải pháp hoàn thiện cơ chế thực thi các quyền hiến định trên cơ sở áp dụng phương pháp tiếp cận dựa trên quyền tại Việt Nam}

\subsection{Một số giải pháp về mặt thể chế}

Một trong những nguyên tắc áp dụng phương pháp tiếp cận dựa trên quyền là tính hợp pháp của các quyền được tiếp cận. Do vậy, cần tiếp tục hoàn thiện hệ thống các quyền hiến định theo hướng tương thích với các nguyên tắc, tiêu chuẩn quốc tế về quyền con người. Hiến pháp 2013 đã đánh dấu nhiều tiến bộ về nhân quyền thông qua việc ghi nhận thêm nhiều quyền mới và củng cố lại những quyền đã có. Tuy nhiên, chế định quyền con người, quyền công dân theo Hiến pháp mới vẫn tồn tại những hạn chế như: còn thiếu một số quyền, tự do cơ bản (ví dụ: quyền không bị bắt làm nô lệ và nô dịch; quyền không bị bỏ tù vì không hoàn thành nghĩa vụ theo hợp đồng; quyền được thừa nhận là thể nhân trước pháp luật ở mọi nơi; quyền đình công; quyền thành lập, gia nhập công đoàn; tự do tư tưởng; quyền được giữ quan điểm riêng mà không bị can thiệp); những khía cạnh chưa rõ ràng tại quy định tại khoản 14.2 về vấn đề tạm đình chỉ thực thi quyền; quy định chưa hợp lý về chủ thể quyền (một số quyền và tự do hiến định như quyền học tập chỉ được ghi nhận đối với "công dân" mà không phải là "mọi người"); ... [12]. Để khắc phục những hạn chế nêu trên, cần tiếp tục sửa đổi và hoàn thiện hiến pháp theo các hướng sau: i) tiếp tục ghi nhận các quyền và tự do cơ bản được quy định trong các văn kiện quốc tế về quyền con người; ii) mở rộng chủ thể quyền từ "công dân" sang "mọi người" đối với một số quyền và tự do hiến định như quyền có nợ ở hợp pháp (Điều 22.1); quyền tự do ngôn luận, tự do báo chí, tiếp cận thông tin, hội họp, lập hội, biểu tình (Điều 25); quyền học tập (Điều 39). Bên cạnh đó, cũng 
cần hoàn thiện chế định giải thích Hiến pháp nhằm thực thi các quy định của Hiến pháp trong đó có các quy định về quyền con người, quyền công dân được thực thi một các thống nhất trên thực tế. Ví dụ, nội dung theo quy định tại khoản 2, Điều 14 về tạm đình chỉ thực thi quyền cũng cần được giải thích, làm rõ ở hai khía cạnh. Thứ nhất, không phải mọi quyền con người, quyền công dân đều có thể tạm đình chỉ thực thi vì theo luật nhân quyền quốc tế, có một số quyền con người không thể bị giới hạn, hạn chế trong mọi trường hợp, bao gồm các quyền: quyền không bị tra tấn, đôi xử hay trừng phạt tàn bạo, vô nhân đạo hay hạ nhục; quyền được suy đoán vô tội; quyền được thừa nhận tư cách thể nhân trước pháp luật và quyền tự do tư tưởng, tín ngưỡng, tôn giáo,... Thứ hai, điều kiện áp dụng tạm dừng thực thi quyền như hạn chế nhằm mục đích bảo đảm quốc phòng, an ninh quốc gia, trật tự, an toàn xã hội, đạo đức xã hội, sức khỏe của cộng đồng cũng cần có sự giải thích theo hướng tính đến căn cứ của từng quyền để phù hợp với luật nhân quyền quốc tế.

Việc hoàn thiện chế định này cần có sự tham gia của người dân với tư cách là chủ thể của hiến pháp, trên cơ sở lưu ý đến các yếu tố: tác động mang tính tổng thể của hiến pháp lên đời sống quốc gia; vai trò của hiến pháp trong việc củng cố các giá trị chung của cộng đồng và các nguyên tắc về quản trị nhà nước; hiệu lực của hiến pháp với tư cách là đạo luật xuất phát từ ý chí đồng thời phản ánh lợi ích và nguyện vọng của người dân.

Bên cạnh đó, Hiến pháp mới ghi nhận tại Điều 14.1: "Ở nước Cộng hòa xã hội chủ nghĩa Việt Nam, các quyền con người, quyền công dân về chính trị, dân sự, kinh tế, văn hóa, xã hội được công nhận, tôn trọng, bảo vệ, bảo đảm theo Hiến pháp và pháp luật". Như vậy, lần đầu tiên, nghĩa vụ của nhà nước đã được hiến định một cách đầy đủ và rõ ràng thể hiện thông qua các nghĩa vụ "công nhận, tôn trọng, bảo vệ và bảo đảm quyền con người, quyền công dân". Quy định không chỉ phù hợp với tỉnh thần của pháp luật nhân quyền quốc tế mà còn góp thay đổi tư duy coi quyền con người, quyền công dân là những thứ nhà nước "ban phát" cho người dân, sang nhận thức chung của cộng đồng quốc tế trong đó xem quyền con người, quyền công dân là những giá trị tự nhiên, vốn có của con người mà nhà nước có nghĩa vụ ghi nhận và bảo đảm [13]. Trên cơ sở quy định này, cần cụ thể hóa hơn nữa trách nhiệm thuộc về các chủ thể công quyền trong việc bảo đảm thực thi các quyền hiến định.

Như vậy, để đảm bảo các nguyên tắc về "tham gia" và "trách nhiệm" theo phương pháp tiếp cận dựa trên quyền, các cá nhân và cộng đồng, đặc biệt là các nhóm yếu thế, phải được trao quyền và tham gia trong quá trình thực thi quyền. Bên cạnh đó, phải xác định chủ thể quyền và những chủ thể có trách nhiệm tương ứng, đánh giá và phân tích năng lực của chủ thể quyền (khả năng thụ hưởng) và của chủ thể có trách nhiệm (khả năng thực thi trách nhiệm) để từ đó xây dựng chiến lược, phương pháp củng cố, nâng cao năng lực tương ứng của các bên [1].

\subsection{Một số giải pháp về mặt thiết chế}

Theo tinh thần của Hiến pháp mới, cơ chế thúc đẩy và giám sát thực hiện các quyền con người, quyền công dân đã bắt đầu hình thành với sự tham gia toàn diện của cả hệ thống chính trị (Quốc hội, Chính phủ, Tòa án Nhân dân, Viện Kiểm sát Nhân dân, Mặt trận Tổ quốc Việt Nam) và các tổ chức, đoàn thể xã hội, góp phần phát hiện, ngăn ngừa và xử lý những vi phạm các quyền hiến định một cách kịp thời. Tuy nhiên, cơ chế này vẫn còn nhiều hạn chế, đặc biệt là trong việc giải quyết những tố cáo và bồi thường những quyền bị vi phạm do thiếu sự tham gia sâu rộng của các tổ chức xã hội, cơ quan truyền thông cũng như sự phối hợp của các cơ quan này với cơ quan dân cử trong việc đảm bảo và thực thi các quyền con người.

Để nâng cao hơn nữa hiệu quả của cơ chế này, thiết lập một thiết chế độc lập với sự tham gia của nhiều thành phần trong xã hội với chức năng giám sát thực thi các quyền hiến định là việc làm cần thiết. Một trong những cơ chế phổ biến tại nhiều quốc gia trên thế giới là cơ quan nhân quyền quốc gia. Thập kỷ qua đã chứng kiến sự tăng trưởng vĩ đại về số lượng và quy mô của các cơ quan nhân quyền quốc gia trên toàn thế 
giới. Những mô hình cơ quan nhân quyền quốc gia phổ biến trên thế giới mà Việt Nam có thể áp dụng bao gồm [15]: Ủy ban nhân quyền; Thanh tra Quốc hội; Cơ quan hốn hợp; Co quan tu vấn; Viện, trung tâm nghiên cúu, được thiết lập và tài trợ bởi nhà nước, và thường giữ vị trí tự quản hoặc bán tự quả) [16] trên cơ sở Hiến pháp và pháp luật quốc gia. Việc thiết lập cơ quan quốc gia có thể là một dấu hiệu cho thấy một quốc gia có thái độ nghiêm túc trong việc thực thi các nghĩa vụ về quyền con người. Cơ quan nhân quyền quốc gia chiếm vị trí độc lập trong các thành tố tư pháp và lập pháp của nhà nước và thường được thiết lập về vị trí thông qua một quá trình lập hiến hoặc sửa đổi Hiến pháp và thiết lập về hoạt động dựa trên pháp luật cụ thể quy định địa vị và nhiệm vụ của các cơ quan này theo tinh thần ghi nhận trong Hiến pháp.

Các cơ quan nhân quyền quốc gia được xem như là yếu tố cốt lõi và không thể thiếu trong Hệ thống bảo vệ quyền con người quốc gia. Khác với các cơ quan nhân quyền quốc tế hoặc các tổ chức phi chính phủ, các cơ quan nhân quyền quốc gia là tiếng nói của quyền con người trong phạm vi quốc gia. Các cơ quan nhân quyền quốc gia có hiệu quả không chỉ trực tiếp thúc đẩy quyền con người, mà còn cung cấp sự giám sát quan trọng và góp phần vào việc thực hiện trách nhiệm giải trình của các cơ quan nhà nước. Các cơ quan nhân quyền quốc gia thường tham gia vào các hoạt động để củng cố các yếu tố khác của Hệ thống bảo vệ nhân quyền quốc gia, chẳng hạn như lĩnh vực tư pháp hoặc an ninh. Điều này có nghĩa là các cơ quan nhân quyền quốc gia có thể coi là điểm kết nối quan trọng khi giải quyết các yếu tố khác của Hệ thống bảo vệ quyền con người quốc gia. [16]

Song song với việc thiết lập cơ quan nhân quyền quốc gia với tư cách một thiết chế hiến định độc lập, cũng cần trao chức năng giám sát việc thực thi nghĩa vụ đảm bảo các quyền con người cho các cơ quan tư pháp nhằm đảm bảo phát hiện và xử lý kịp thời các hành vi vi phạm nhân quyền từ chủ thể công quyền. Theo tinh thần của luật nhân quyền quốc tế, tư pháp độc lập được coi là một nguyên tắc rất quan trọng trong việc bảo vệ các quyền con người. Do vậy, ngoài việc ghi nhận tính độc lập của tòa án trong Hiến pháp, Việt Nam còn cần đưa ra những biện pháp thực tế nhằm bảo đảm và nâng cao tính độc lập của tòa án trên thực tế [17]. Tóm lại,tăng cường các thiết chế giám sát thực thi các quyền hiến định chính là biện pháp hữu hiệu nhằm bảo đảm tính chịu trách nhiệm của các chủ thể công quyền trong việc tuân thủ và thực hiện các quy định hiến pháp về quyền con người trên thực tế.

Bên cạnh hoạt động giám sát, cũng cần xây dựng các cơ quan chuyên trách về thúc đẩy các quyền con người mà trọng tâm là hoạt động giáo dục về nhân quyền. Mặc dù ở nước ta, các hoạt động giáo dục nhân quyền đã và đang thực hiện ở cả trong và ngoài hệ thống nhà trường và có những tác động tích tực trong việc nâng cao nhận thức về quyền con người đối với cả các chủ thể nhà nước và phi nhà nước. Tuy nhiên, phạm vi và trình độ giáo dục nhân quyền ở Việt Nam vẫn còn ở mức hạn chế và có nhiều khía cạnh chưa bắt kịp với xu hướng phát triển chung trên thế giới cũng như ứng nhu cầu giáo dục nhân quyền ở trong nước trong bối cảnh hội nhập và toàn cầu hóa. Nguyên nhân của những hạn chế này có lẽ là từ nhận thức chưa đầy đủ về tầm quan trọng của giáo dục nhân quyền. Do vậy, việc thiết lập một cơ quan đầu mối về giáo dục nhân quyền nhằm thu hút nguồn nhân, vật lực, kiến thức, kinh nghiệm và tài liệu sẽ đóng vai trò thiết thực trong việc nâng cao nhận thức về nhân quyền trong cộng đồng [18].

Như vậy, áp dụng phương pháp tiếp cận dựa trên quyền chính là phương thức thúc đẩy các quyền hiến định được bảo đảm trong thực tế trên cơ sở nâng cao nhận thức cũng như khả năng khẳng định và thụ hưởng quyền của chủ thể quyền, đồng thời tăng khả năng chịu trách nhiệm của chủ thể có trách nhiệm thực thi quyền.

\section{Tài liệu tham khảo}

[1] OHCHR, Frequently Asked Questions on the Human Rights-based Approach in Development Cooperation, 2006, p.1.

https://www.ohchr.org/Documents/Publications/F AQen.pdf (Truy cập: 15/11/2019). 
[2] United Nation Vietnam, Giải thích sơ lược về Phương pháp tiếp cận dựa trên cơ sở Quyền Con người (Tài liệu dành cho Cán bộ Liên hợp quốc tại Việt Nam). http://www.un.org.vn/images/stories/pub_trans/H RBA_Toolkit_-_Vietnamese.pdf (Truy cập: $15 / 11 / 2019)$.

[3] Ủy ban về Quyền con người, Bình luận chung số 25 (1996).

[4] Trung tâm Nghiên cứu QCN \&QCD, Khoa Luật, ĐHQGHN, Giới thiệu về các quyền dân sự và chính trị, NXB Hồng Đức, 2012.

[5] Secretary-General, Guidance Note of the Secretary-General: United Nations Assistance to Constitution-making Processes. https://www.un.org/ruleoflaw/files/Guidance_Not e_United_Nations_Assistance_to_Constitutionmaking_Processes_FINAL.pdf (Truy cập: 15/11/2019).

[6] World Bank, Governance: The World Bank's Experience, Washington DC, 1994, p. VII.

[7] Secretary-General, Guidance Note of the Secretary-General: UN Approach to Rule of Law Assistance.

[8] Secretary-General, Guidance Note of the SecretaryGeneral: United Nations Assistance to Constitutionmaking Processes.

https://www.un.org/ruleoflaw/files/Guidance_Not e_United_Nations_Assistance_to_Constitutionmaking_Processes_FINAL.pdf (15/11/2019).

[9] Secretary-General, Guidance Note of the Secretary-General on Democracy.

[10] United Nations Viet Nam, Human rights and the human rights-based approach. http://www.un.org.vn/en/what-we-do-mainmenu203/cross-cutting-themes-human-rights.html (15/11/2019).

[11] OHCHR, Human rights and Constitution making, New York \& Geneva, 2018, p. 3 - 10. https://www.ohchr.org/Documents/Publications/C onstitutionMaking_EN.pdf (15/11/2019).

[12] Vũ Công Giao, Những tiến bộ và hạn chế trong chế định quyền con người, quyền công dân của Dự thảo 3 Hiến pháp 1992 sửa đổi năm 2013, Tạp chí Khoa học ĐHQGHN, Luật học,Tập 29, Số 3 (2013) 52-63.

[13] Đào Trí Úc - Vũ Công Giao, "Khái quát những điểm mới của Hiến pháp năm 2013” trong cuốn Bình luận khoa học Hiến pháp nước Cộng hòa xã hội chủ nghĩa Việt Nam Việt Nam năm 2013 (Sách chuyên khảo), NXB ĐHQGHN, 2014.

[14] Nguyễn Thùy Dương, "Tiếp cận dựa trên quyền trong xây dựng, thực hiện chính sách, pháp luật về quyền của phụ nữ ở Việt Nam" trong cuốn "Tiếp cận dựa trên quyền con người - Lý luận và thực tiễn" (Sách chuyên khảo), NXB ĐHQGHN, 2016.

[15] Lã Khánh Tùng, Cơ quan Nhân quyền quốc gia 101 Câu hỏi - đáp, NXB Hồng Đức, 2017, tr. 5-10.

[16] Strengthening the National Human Rights Protection System.

http://www.globalequality.org/storage/documents/ pdf/manual\%20nhrps-web.pdf (15/11/2019).

[17] Khoa Luật, ĐH QGHN, Giới thiệu các văn kiện quốc tế về quyền con người, NXB Lao động - xã hội, 2011, tr.821-824.

[18] Lã Khánh Tùng, Vũ Công Giao, Bài viết “Giáo dục về Quyền con người ở Việt Nam hiện nay” trong Kỷ yếu Hội thảo Kết nối Nghiên cứu về Quyền con người, 8/2008. 